\title{
Feasibility of pedigree recording and genetic selection in village sheep flocks of
}

Solomon Gizaw ${ }^{15 *}$, Shenkute Goshme ${ }^{1}$, Tesfaye Getachew ${ }^{1}$, Aynalem Haile, Barbara ${ }^{2}$

${ }^{1}$ Debre Birhan Agricultural Research Centre, P.O. Box 112, Debre Birhan, Ethiopia

${ }^{3}$ Animal Breeding and Genomics Centre, Wageningen University, P.O. Box 338, 6700 AH, Wageningen,

${ }^{4}$ University of Hohenheim, Department of Animal Breeding and Husbandry in the Tropics and Subtropics,

*Corresponding author: E-mail: s_gizaw@yahoo.com; s.gizaw@live.com 


\section{Abstract}

Pedigree recording and genetic selection in village breeding flocks has been deemed

4 infeasible by researchers and development workers. This is mainly due to the difficulty of sire identification under uncontrolled village breeding practices. A pilot village-based genetic

6 improvement program as well as a central nucleus breeding flock has been established for Menz sheep of Ethiopia. A performance and pedigree recording scheme was developed for the

8 village-based genetic improvement activities. Selection of breeding stock in the village flocks was based on phenotype of the candidates or farmers subjective criteria; and response to 10 selection was estimated based on phenotypic trends across generations. In this paper we evaluate the reliability and accuracy of village-based pedigree recording by comparing genetic

12 parameter estimates and their standard errors estimated from the village and the nucleus datasets. Effectiveness of selection was evaluated based on trends in breeding values over

14 generations. The village herd boys were able to identify the sires of $80 \%$ of the matings that took place between 2002 and 2004. The coefficients of variation and the heritability estimates

16 and their standard errors for 6-month weights recorded in the villages and nucleus flocks were very similar. There were increasing trends in the average estimated breeding values over generations for birth, 3-month and 6-month weights in the village flocks. The third generation lambs had a genetic superiority of $1.08 \mathrm{~kg}$ over the base generation lambs in 6-month weight. Similar trends were observed for the phenotypic values over generations. These results have a number of implications. The major finding is that the pedigree recorded in the village flocks is

22 reliable. Secondly, appreciable genetic improvement could be achieved from selection using 
farmers' subjective criteria. Thirdly the use of adjusted phenotypic values as an approximation

2 to breeding values and to estimate responses to selection in village-based breeding programs could be justified. Furthermore, genetic parameters such heritability can be estimated based on

4 village recording. Reliable village recording system can be organized and implemented by farmer enumerators recruited from the village community. However, this requires designing

6 innovative recording scheme suitable to smallholder village breeding practices and a continuous monitoring by expert breeders from research and development institutes.

\section{1. Introduction}

The common characteristic of livestock breeding under smallholder systems in

10 developing countries is the absence of structured genetic improvement programs (Kosgey and Okeyo, 2007). This could partly be due to the difficulty of implementing effective breeding

12 programs under smallholder conditions. Earlier attempts focused on central nucleus breeding flocks to generate and disseminate genetic improvement to village flocks (Ponzoni, 1992; Gizaw

14 et al., 2007). Recently, village-based breeding programs are being attempted (Wurzinger et al. 2008; Gizaw et al. 2009; Gizaw et al. 2011; Aynalem et al., 2011; Mirkena et al., 2011). Implementation of effective village-based selective breeding programs under smallholder livestock farming systems is indeed a challenge (Philipsson et al., 2011; Rege et al., 2011). The major challenges include selecting genetically superior breeding stock and estimating responses to selection based on accurate estimates of breeding values. The underlying bottleneck is the difficulty of recording reliable and accurate pedigree and performance data required to estimate breeding values. 
A pilot village-based genetic improvement program (Gizaw et al., 2011) as well as a

2 central nucleus breeding flock (Gizaw et al., 2007) has been established for Menz sheep of Ethiopia. A performance and pedigree recording scheme was developed for the village-based

4 genetic improvement activities. Selection of breeding stock in the village flocks was based on phenotype of the candidates or farmers subjective criteria; and response to selection was estimated based on phenotypic trends across generations. In this paper we evaluate the villagebased performance and pedigree recording in terms of its reliability and accuracy to estimate

8 genetic parameters, predict breeding values and estimate genetic trends across generations; So far, these have been estimated only based on data collected in flocks maintained in research 10 centers under controlled breeding practices.

\section{Materials and methods}

\section{$12 \quad$ 2.1. Village flocks}

A pilot village-based breeding program was set up in 2009 in two villages in Menz sheep

14 breeding area in the subalpine highlands of Ethiopia. The area is subalpine with an altitude of about 3200 m above sea level. The objective was to improve the genetic merits of Menz sheep

16 in growth traits so as to increase their contributions to the livelihoods of their keepers, and by so doing the competiveness and long-term development and use of Menz sheep breed.

The breeding program was organized as a cooperative breeding group based on a conceptual framework described elsewhere by Gizaw et al. (2009) and Gizaw et al. (2011b). The program was designed to benefit from the existing sheep production practices, while ensuring 
that the existing bottlenecks such as inbreeding, uncontrolled mating, pedigree recording and

2 small household flock sizes were taken into account and overcome. The breeding group was formed by two adjacent villages whose flocks share common grazing fields and watering points,

4 hence can be considered as one big interbreeding population, separate from other village populations. The group consisted of fifty farmers with a total breeding flock of 1005 ewes. The

6 breeding group was sub-grouped into 17 ram groups each comprising 2 to 4 farmers. The ram groups were expected to use a ram communally. The formation of the ram groups was based

8 on mapped social structure (i.e. settlement, social connections) and grazing management of their flocks. Bylaws were drafted to guide and govern the cooperators and the cooperative. The 10 bylaws include regulations on membership and breeding activities including recording, selection, use and management of breeding rams.

12 Recording

One of the participating farmers in the project villages was recruited and trained as an 14 enumerator. His role was to coordinate the breeding program and collect pedigree and performance data from the participating village flocks. All animals in the villages were uniquely 16 identified using ear tags. Data collection commenced prior to the start of the first round of selection. Baseline information collected include parity of the ewes using farmer-recall method; age of the ewes based on their dentition; date of birth, dam identity, birth weight and subsequent weights of lambs sired by non-selected village rams at the start of the breeding program. The performance of lambs sired by the unselected village sires served as a baseline or contrasts against which the genetic progress resulting from selection was assessed. 
After the selection activity started, data on matings, lambings and body weights were

2 recorded. Mating records were collected as follows: the enumerator collects information from the flock owners on matings that took place within the breeding groups. Matings that took

4 place in grazing areas were recorded or reported to the enumerator by the herdsboys to identify sires of new born lambs. The enumerator makes rounds of visits to the villages every morning to record lambs born, identify lambs by ear tags, and weigh the newborn. The lambs were also weighed at three and six months of age.

\section{Selection and mating}

A one-tier breeding structure was adopted, i.e. selection was implemented in the whole village sheep population. Selection was implemented across villages and flocks. All six month old ram lambs from all flocks in the project villages were evaluated together as cohorts.

12 Selection of the best young rams was planned to be based on their six-month weight corrected for non-genetic factors, and to subject these criteria further to farmers' selection criteria which

14 have been defined earlier (Getachew, 2008; Gizaw et al. 2010). Farmers however put heavier weights on their own subjective morphometrics-type of criteria (i.e. pelvic width and body length) to select the rams. The selected rams were assigned to ram groups following a family mating plan to avoid inbreeding (Croston and Pollot, 1994). The ram groups were organized in such a way that the rams would be used and managed communally. Mating was planned and restricted to within the ram groups. However, some matings could happen across the ram groups. All unselected ram lambs and old breeding rams were culled at each round of selection, castrated fattened and sold to establish a revolving fund which was then used to compensate or pay for the selected rams. 


\subsection{Nucleus flock}

A nucleus flock of Menz sheep was established in 1998 at Debre Birhan Agricultural Research Center and substantial genetic gains have been achieved (Gizaw et al. 2011a).

4 Selection of breeding stocks and evaluation of genetic progress was based on breeding values for yearling weight estimated using BLUP procedure. Mating was arranged in single-sire mating groups. Recording included dates, body weights and pedigrees.

\subsection{Evaluation of village recording and selection}

The basis for evaluating the reliability and accuracy of village-based recording was comparison of genetic parameters (heritability and correlations) estimated from the village data set with estimates from the nucleus data set recorded under controlled research conditions. The criteria used were the coefficients of variation of body weight records, genetic

12 parameter estimates and their standard errors. The reliability of pedigree recording and effectiveness of genetic selection in village flocks was evaluated based on estimates of breeding

14 values and the genetic progress achieved in village flocks.

The village and nucleus datasets respectively consisted of 1442 and 1948 records for birth weight, 1247 and 1597 for 3-month weight, and 1098 and 1320 for 6-month weight. The 3-month and 6-month records were adjusted to a standard 90 and 180 days weights. The two data sets were separately fitted to the same analysis model to estimate genetic parameters and breeding values. Variance components and best linear unbiased prediction (BLUP) of breeding values for birth, three month and six month weights were obtained from the solutions for the random animal genetic effect in a multi-trait individual animal model analysis. The data were 
analyzed using WOMBAT Version 01-11-2011 (Meyer, 2009). The following model was fitted to

2 the data:

$\mathbf{Y}_{i}=\mathbf{X}_{i} b_{i}+\mathbf{Z}_{i} \mathrm{a}_{i}+e_{i}$

4 where $\boldsymbol{Y}_{i}$ is vector of observations for trait ${ }_{i}, b_{i}$ denotes a vector of fixed effects for trait ${ }_{i}$ (sex, season and year of lamb birth, and dam parity), $a_{i}$ is a vector of random animal effects for trait

$6{ }_{i}, e_{i}$ is vector of random residual effects for trait ${ }_{i}$, and $\boldsymbol{X}_{i}$ and $\mathbf{Z}_{i}$ are incidence matrices relating records for trait $;$ to fixed effects and random animal effect, respectively.

\section{$8 \quad 3 . \quad$ Results}

\subsection{Pedigree and performance Recording}

The percentage of lambs whose birth date, sex, dams and sires were identified and recorded in a cooperative breeding village and a nucleus breeding flock is shown in Table 1 . The

12 results are very similar for the village and nucleus data sets, except the percentage of sires identified. The percentage of the sires identified in the village flock was lower than in the

14 nucleus flock. However, the herd boys were able to identify the sires in about $80 \%$ of the matings.

16 Table 1. Percentage of new born lambs with their birth date, sex and pedigree identified and recorded at a cooperative breeding village in Menz region and nucleus breeding flock at Debre Birhan Research Center, Ethiopia

\begin{tabular}{lcccc}
\hline Birth date & Sex & Dams & Sires & Doubtful \\
recorded & identified & identified & identified & dam/sire \\
& & & \\
\hline
\end{tabular}




\begin{tabular}{lccccc}
\hline Village data set & 97.86 & 97.86 & 97.86 & 79.49 & 1.10 \\
Nucleus data set & 100.00 & 99.89 & 99.89 & 99.78 & 0.27 \\
\hline
\end{tabular}

Two measures of accuracy were considered to evaluate the reliability of performance recording in a cooperative village flocks and a nucleus breeding flock (Table 2). The coefficients

4 of variation for 6-month and 3-month weights recorded by a farmer enumerator in the cooperative village were very similar to the records collected in the nucleus flock by the

6 research staff. However, the coefficients of variation for the village data set were lower than the nucleus data set. Similarly, the standard deviations from the two data sets were very 8 similar, except for birth weight.

Table 2. Coefficients of variation (CV), means and standard deviations (SD) of body weight 10 measurements recorded in village and nucleus flocks

\begin{tabular}{lccccccc}
\hline & \multicolumn{2}{c}{ Birth weight } & \multicolumn{2}{c}{3 month weight } & \multicolumn{2}{c}{6 month weight } \\
& Village & Nucleus & Village & Nucleus & Village & Nucleus \\
& data set & data set & data set & data set & data set & data set \\
& 1400 & 1953 & 1115 & 1599 & 1045 & 1322 \\
\hline No. of observations & 10.55 & 19.73 & 18.63 & 21.44 & 15.38 & 19.43 \\
CV (\%) & 2.41 & 2.24 & 8.92 & 8.69 & 13.04 & 11.08 \\
Mean (kg) & 0.29 & 0.47 & 2.09 & 2.30 & 2.26 & 2.51 \\
SD (kg) & & & & & & & \\
\hline
\end{tabular}

\subsection{Estimates of genetic parameters}


The heritability estimates for body weight at six months of age (the selection criterion in

2 Menz sheep breeding program) estimated from the village and nucleus data sets were almost identical (Table 3). The standard errors of the heritability estimates for the village and nucleus

4 data sets were also very similar for all the traits studied. The heritability of birth weight based on the village data set was however lower than that estimated from the nucleus data set.

The genetic and phenotypic correlations of six month weight with both birth weight and three month weight were higher than the correlations between birth and three month weights

8 (Table 4). These correlation trends were similar for both the village and nucleus data sets. However, in all cases the correlations estimated from the nucleus data set were higher than those estimated from the village data set. The standard errors of the correlation estimates from the village data set were higher than the estimates from the nucleus data set.

12 Table 3. Heritabilities and their standard errors estimated from village and nucleus data sets

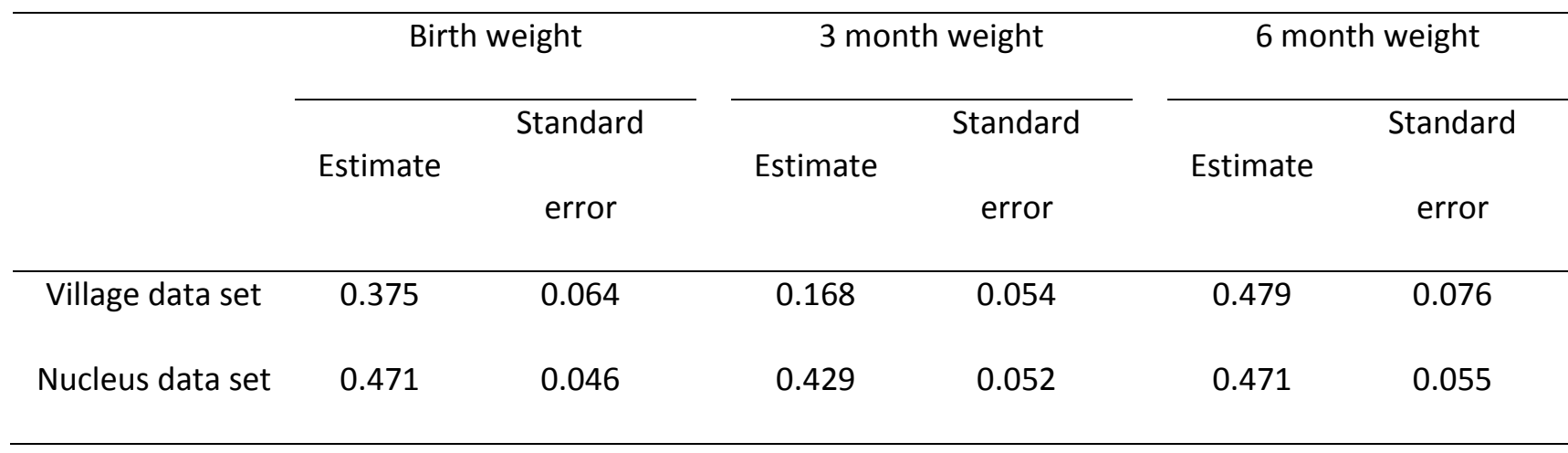

Table 4. Genetic (above diagonal) and phenotypic (below diagonal) correlations and their 14 standard errors estimated from village and nucleus data sets

\begin{tabular}{|c|c|c|c|c|c|}
\hline \multicolumn{2}{|c|}{ BWT } & \multicolumn{2}{|c|}{ WWT } & \multicolumn{2}{|c|}{ SWT } \\
\hline Village & Nucleus & Village & Nucleus & Village & Nucleus \\
\hline
\end{tabular}




\begin{tabular}{ccccccc}
\hline BWT & & & $0.460 \pm 0.171$ & $0.603 \pm 0.071$ & $0.598 \pm 0.114$ & $0.633 \pm 0.068$ \\
WWT & $0.197 \pm 0.030$ & $0.436 \pm 0.024$ & & & $0.817 \pm 0.101$ & $0.995 \pm 0.010$ \\
SWT & $0.248 \pm 0.031$ & $0.442 \pm 0.025$ & $0.525 \pm 0.023$ & $0.809 \pm 0.010$ & & \\
& & & & & & \\
\hline
\end{tabular}

BWT birth weight; WWT 3-month weight; SWT 6-montth weight

\section{$2 \quad$ 3.3. Estimates of genetic progress}

Genetic progress per generation achieved from selection for 6-month weight in village

4 flocks is presented in Figure 1. There were increasing trends in the average estimated breeding values of birth weight, 3-month weigh and 6-month weight. The third generation lambs had a

6 genetic superiority of $1.08 \mathrm{~kg}$ over the base generation lambs in 6 -month weight. The base generation lambs are those lambs sired by non-selected rams at the beginning of the breeding

8 program. The average least squares means for the base, first, second and third generations respectively were $11.61,13.24$ and $14.30 \mathrm{~kg}$ for 6-month weight, 8.08, 9.13 and $9.96 \mathrm{~kg}$ for 3-

10 month weight, and 2.18, 2.47, 2.56, and 2.69 for birth weight. The level of inbreeding was low across generations; 0.0, 0.0017, 0.0006, and 0.0023 for the base, first, second and third 12 generations, respectively. 


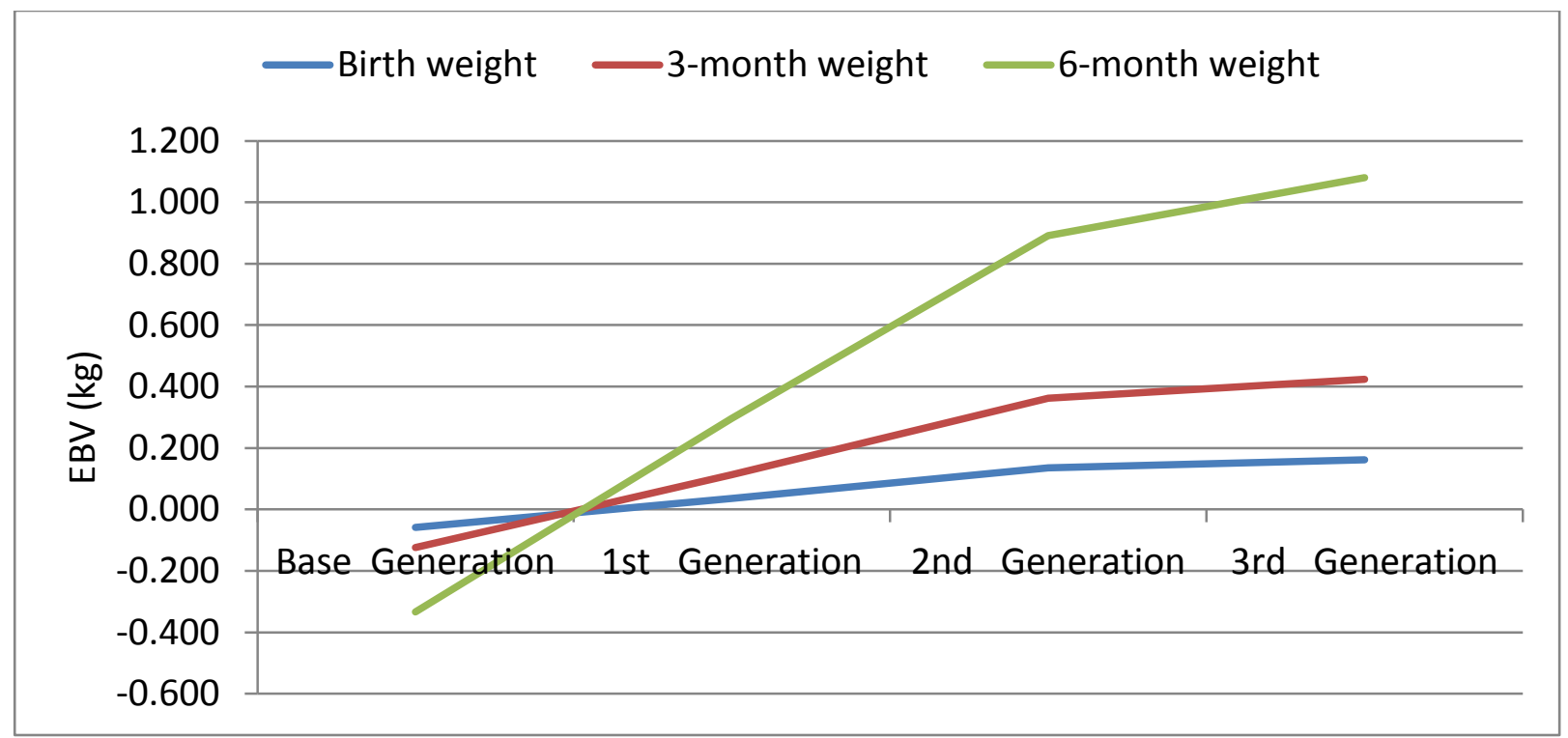

2 Figure 1. Genetic progress per generation (Estimated breeding values, EBV) resulting from selection for 6-month weight in a cooperative breeding village in Menz region, Ethiopia

\section{4. Discussion}

Pedigree recording in village breeding flocks has been deemed infeasible by researchers and development workers. This is mainly due to the difficulty of sire identification under uncontrolled village breeding practices; uncontrolled breeding practices is common in Menz region with $44.1 \%$ of the farmers practicing uncontrolled breeding (Gizaw et al., 2009). Genetic selection in smallholder farming systems has thus remained a challenge so far. As a result, selection of breeding stock and estimation of genetic progress in village-based breeding programs had to be based on phenotypic trends, which might be less reliable than estimates

12 obtained from BLUP breeding values.

The data from the current study show that pedigree and performance recording can be 14 reliably undertaken in village flocks of smallholder farmers, so long as this is done by one of 
their own. The percentage of lambs whose birth date, sex and dams identified and recorded in

2 cooperative breeding villages was found to be as high as the pedigree recorded in a nucleus flock maintained in a research centre. The farmers were also able to identify the sires of about

$480 \%$ of the lambs born in the villages. The current results are in full agreement with a previous survey of farmers' sheep breeding practices in Menz region, where farmers claim that $97.5 \%$ 6 and $36.3 \%$ of farmers in Menz region can identify the dams and sires of their lambs (Gizaw et al. 2009). In fact, the current result indicates that sire identification in village breeding can be more 8 feasible than the farmers thought or practiced if suitable pedigree recording is devised.

The validity of the performance and pedigree records collected in the cooperative 10 breeding villages was put under some rigorous assessment. The coefficient of variation (CV), which is a function of the means and their standard errors, of body weight measurements were 12 considered as a measure of their reliability and/or accuracy. It is suggested that the CV instead of the standard deviation should be used for comparison between data sets with different units 14 or widely different means, as the CV would be constant over a large range of measurements. Accordingly, the 3-month and 6-month weight data could be considered reliable and thus used to compare the respective village collected data to those collected in the nucleus flock.

Genetic parameters such as heritabilities and genetic correlations have so far been estimated based on data collected on flocks maintained in research centers under controlled mating. No genetic parameters estimated based on recording in smallholder sheep locks have been reported. The striking similarity of the heritability estimates for 6-month body weight and particularly their standard errors (which can be taken as a measure of reliability) from the 
village and nucleus datasets is a good indicator for the feasibility of the village recording system

2 adopted in our breeding program. The current estimates are also within the range of estimates in the literature (Safari et al. 2005; Gizaw and Joshi, 2004). The discrepancy between some of

4 the genetic parameter estimates, particularly estimates for birth weight, from the two datasets could be explained by fact that the heritability is not only a genetic property of a population, but also of the distribution of environmental values that the population experiences. However, recording birth weights under village conditions is difficult and may not be reliable.

Results of the positive genetic trends and the reliable genetic parameters estimates for the village dataset in this study have a number of implications. The major finding is that when participatorily implemented, village recording systems can be highly reliable and effective. Secondly, appreciable genetic improvement could be achieved from selection using farmers' subjective criteria. This can be explained by the high genetic correlation between body weights and linear size traits such as pelvic width (Janssens and Vandepitte, 2004; Afolayan et al., 2007; Gizaw et al. 2008). The phenotypic trends estimated in the current study correspond very well to the genetic trends. This could thus justify the use of phenotypic values (duly adjusted for non-genetic factors) as an approximation to breeding values and to estimate responses to selection in village-based breeding programs. Furthermore, genetic parameters such heritability can be estimated based on village recording, which has so far been estimated from recording in nucleus flocks.

Nonetheless, our results also indicate that genetic selection which requires pedigree recording and estimation of breeding values to select breeding animals and estimate genetic 
progress is also feasible under village conditions too. Reliable village recording system can be

2 organized and implemented by farmer enumerators recruited from the village community. However, recording in village flocks requires designing simple but innovative recording

4 schemes, which if agreed upon and implemented in participatory manner would be feasible and suitable to smallholder village breeding practices. This could be made even more sustainable if faster feedbacks were enabled, by innovatively using emerging cell phone based recording technologies such as ODK (open data kit), thus allowing more continuous monitoring by expert

8 breeders from research and development institutes. This would further enable timely feedbacks of the results and implications to the farmers, thus provide the key incentive for recording that has hitherto remained elusive in low-input livestock production systems where elaborate supportive organizational structure and infrastructure for western world type of 12 recording are poor or non-existent.

\section{Acknowledgements}

We appreciate the efforts made by the cooperative farmers, particularly the farmerenumerator Beletew, in the data collection. We sincerely thank the farmers who spared their time and flocks for this work. Contributions of the staff at Debre Birhan Agricultural Research Centre are gratefully acknowledged. This paper is produced as part of the first author's postdoctoral research funded by DAAD/ILRI. The project is financed by the Amhara Regional Agricultural Research Institute and the Ethiopian Institute of Agricultural Research. 


\section{References}

2 Afolayan, R.A., Pitchford, W.S., Deland, M.P.B., Mckiernan, W.A., 2007. Breed variation and genetic parameters for growth and body development in diverse beef cattle genotypes. Animal 1, 13-20.

Aynalem Haile, Maria Wurzinger, Joaquín Mueller, Tadele Mirkena, Gemeda Duguma, Okeyo Mwai, Johann Sölkner and Barbara Rischkowsky, 2011. Guidelines for Setting up Community-based Sheep Breeding Programs in Ethiopia. ICARDA - tools and guidelines No.1. Aleppo, Syria, ICARDA.

Croston and Pollot, 1994. Planned sheep production. Oxford Press, London.

Dodd, C.J. and Delahunty, J.R. 1983. Selection efficiency in ram breeding flocks. Proc. N.Z. Soc. Anim. Prod. 43; 193-196.

Getachew T 2008. Characterization of Menz and Afar Indigenous sheep breeds of smallholders and pastoralists for designing community-based breeding strategies in Ethiopia. MSc, Haramaya University.

Gizaw S and Joshi B.K. 2004. Estimates of genetic parameters for growth traits in Menz and Awassi x Menz crossbred sheep in Ethiopia. Indian Journal of Animal Sciences 74(8):864867.

Gizaw S, Awigchew K, Yami A. 2011b. A practical guide for village-based sheep and goat cooperative breeding scheme. ESGPIP Technical Bulletin 42.

Gizaw S, Getachew T, Haile A, Dessie T. 2011a. Congruence between selection of breeding rams based on breeding values for production traits and farmers ram choice criteria. Animal 5:7, 995-1001.

Gizaw S, Komen H and van Arendonk JAM 2009. Optimal village breeding schemes under smallholder sheep farming systems. Livestock Science 124, 82-88. 
Gizaw S, Komen H and van Arendonk JAM 2010. Participatory definition of breeding objectives and selection indexes for sheep breeding in traditional systems. Livestock Science 128, 6774.

4 Gizaw S, Lemma S, Komen H and van Arendonk JAM 2007a. Estimates of genetic trends and genetic parameters for live weight and fleece traits in Menz sheep. Small Ruminant Research 70, 145-153.

Gizaw S., Komen, H., van Arendonk, J.A.M., 2008. Selection on linear size traits to improve live weight in Menz sheep under nucleus and village breeding programs. Livestock Science 118:92-98.

Gizaw, S., Komen, H., van Arendonk, J.A.M., 2008. Selection on linear size traits to improve live weight in Menz sheep under nucleus and village breeding programs. Livestock Science 118:92-98.

Gizaw, S., Van Arendonk JAM, Komen H., Windig J.J., Hanotte O. 2007b. Population structure, genetic variation and morphological diversity in indigenous sheep of Ethiopia. Animal Genetics 38:621-628.

Janssens, S., Vandepitte, W., 2004. Genetic parameters for linear measurements and linear type traits in Belgian Bleu du Maine, Suffolk and Texel sheep. Small Rumin. Res. 54, 13-24.

Janssens, S., Vandepitte, W., 2004. Genetic parameters for linear measurements and linear type traits in Belgian Bleu du Maine, Suffolk and Texel sheep. Small Rumin. Res. 54, 13-24.

Kinghorn, B. 2007. GENUP, Version 5.5. http://metz.une.edu.au/ bkinghor.

Kosgey IS 2004. Breeding objectives and breeding strategies for small ruminants in the tropics. PhD, Wageningen University.

Kosgey, I.S. and Okeyo, A.M. 2007. Genetic improvement of small ruminants in low input, smallholder production systems: technical and infrastructural issues. Small Ruminant Research70:76-88. 
Lauvergne, J.J., Bourzat, D., Minvielle, F., 2000. Using morphometric indices to map goat resources. In: The origins and development of African livestock: Archaeology, genetics, linguistics and ethnography (ed. By R M. Blench and K. C. MacDonald), pp. 290-301. Univ. College London Press, London.

Mirkena, T., G. Duguma, A. Willam, M. Wurzinger, A. Haile, B. Rischkowsky, A.M. Okeyo, M. Tibbo, J. Solkner. 2011. Community-based alternative breeding plans for indigenous sheep breeds in four agro-ecological zones of Ethiopia. Journal of Animal Breeding and Genetics, doi: 10.1111/j.1439-0388.2011.00970.x.

Mueller JP and James JW. 1984. Design and evaluation of progeny testing in open nucleus breeding systems. Anim. Prod. 38: 1-8.

Nicoll, G.B., Bodin, L., Jonmundson, J.V. 1986. Evaluation of inter-flock genetic improvement programs for sheep and goats. 3rd World Congress on Genetics Applied to Livestock Production. Paper 47. http://digitalcommons.unl.edu/wcgalp/47.

Philipsson J., Rege, J.E.O., Zonabend E. and Okeyo A.M. 2011. Sustainable breeding programmes for tropical farming systems In: Animal Genetics Training Resource, version 3, 2011. Ojango, J.M., Malmfors, B. and Okeyo, A.M. (Eds). International Livestock Research Institute, Nairobi, Kenya, and Swedish University of Agricultural Sciences, Uppsala, Sweden

Ponzoni RW 1992. Genetic improvement of hair sheep in the tropics. FAO Animal Production and Health Paper 101, Rome, Italy, 168 pp.

Rege, J.E.O., Marshall, K., Notenbaert, A., Ojango, J.M.K. and Okeyo, A.M., 2011. Pro-poor animal improvement and breeding-What can science do? Livestock Science136(1):15-28.

22 Rodríguez CT and Quispe JL. 2007. Domesticated camelids, the main animal genetic resource of pastoral systems in the region of Turco, Bolivia. In Tempelman KA and Cardellino RA (Eds.) 
Safari, E., Fogarty, N. M., Gilmour, A. R. 2005.A review of genetic parameter estimates for wool, growth, meat and reproduction traits in sheep. Livest. Prod. Sci. Livest. Prod. Sci. 92, 27189.

4 Sölkner J, Nakimbugwe H and Valle Zarate A 1998. Analysis of determinants for success and failure of village breeding programs. Proceedings of the 6th World Congress on Genetics 6 Applied to Livestock Production 25, 273-281. 